\title{
Thin line of difference between laissez faire leadership and absentee leader
}

\section{Bhumika Achhnani $^{1^{*}}$}

\author{
${ }^{\mathbf{1}}$ Associate Professor, Faculty of Business Management, Marwadi University, Rajkot, Gujarat, India
}

*Corresponding Author: Bhumika Achhnani

Email: drbhumikaachhnani@gmail.com

\section{Concept of Leadership}

Prentice defined leadership as "the accomplishment of a goal through the direction of human assistants" and an effective leader as one who can recognize people's motives and solicit employee participation in a way that aligns individual desires and concerns to the group's objective.

Leaders influence the organizational productivity by inspiring the team members. Tannenbaum and Schmidt ${ }^{1}$ proposed leadership continuum theory which highlights that there are many classifications of leadership. In this context autocratic or democratic are extremes and leadership practices in actual life conditions lie somewhere between these two extremes. Individual leadership styles listed within the continuum include telling, selling, consulting, and joining leadership styles.

The full range leadership model ${ }^{2}$ integrates dimensions of charismatic, transformational, contingent reward, management-by-exception (MBE) and laissez-faire leadership into one single theory and opens up a new era of comprehensive leadership research.

The original model comprised four factors, however it was revised after repeated empirical application. The latest model consists of nine single-order factors accounting for leadership effectiveness, active and passive leadership. ${ }^{3}$ Four transformational leadership factors, three transactional and one passive leadership factor are encompassed in the model.

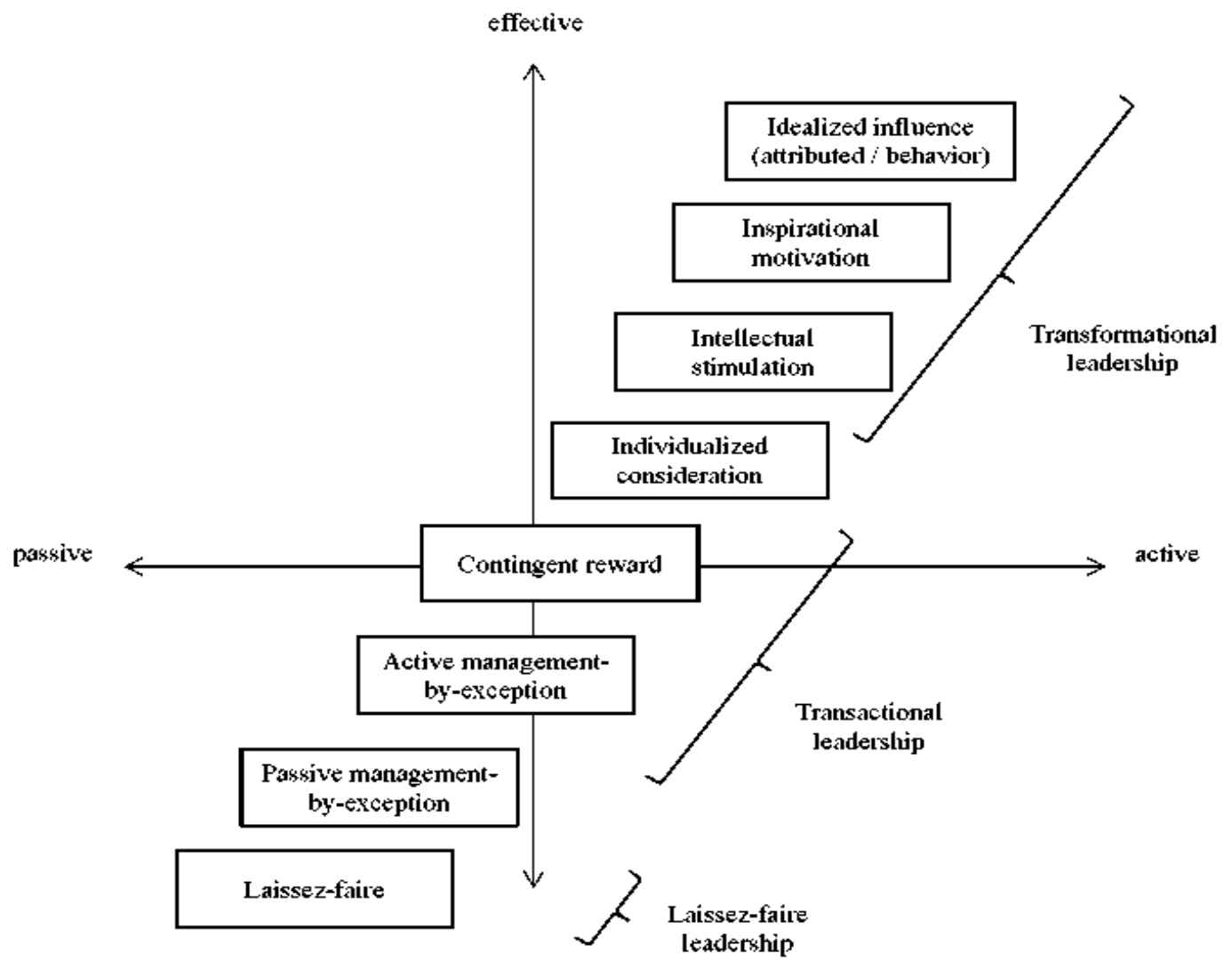

ineffective

Source: Bass and Avolio (1995) 
As several research papers suggest, transformational leadership facilitates to involve employees more than a transactional type of leadership., ${ }^{4,5}$ In transactional leadership, employees are enabled to see themselves as a part of the team. Employees who feel that they are part of the organisation are found to be more committed to their roles and are found to be more effective in achievement of organisational goals. Transformational leaders on the other hand can make the followers put organisational goals over their own goals and interest. Such type of leaders is found to be very passionate and lively. The most ineffective and passive type of leadership is Passive Laissez-Faire Leadership as shown in the figure above.

\section{Passive Laissez-Faire Leadership}

The term "laissez-faire" is a French term which is mostly used in economics and political sciences to describe a policy of slightest governmental intervention in the economic affairs of people and society (Encyclopædia Brittannica, nd). In leadership literature, laissez-faire implies a "hands-off, let things-ride" approach ${ }^{7}$ to shaping individuals in the workplace.

Passive laissez-faire leadership is built on trust. Passive laissez-faire leader abandons the duties and avoids taking decisions. Especially, such leaders give their decisionmaking power to managers and employees. Such type of leadership is acceptable if the employees are specialists in their field. Many research studies claim that laissez-faire leadership in the organization results in negative consequences and stress among employees. This type of leaders are passive leaders, who are not strategy-oriented which are opposite to the characteristics of the transformational and transactional leaders.

This type of leaders does not control their subordinates directly. Most of the team members are supposed to be highly experienced and hence it is assumed that they do not need control and regulation. These types of leaders also do not provide continuous feedback to their team members, which plays a significant role in successful teamwork. The members also feel lack of communication and feedback for improvement which leads to delays in project completion. This leadership style looks like "impoverished management" described by Blake and Mouton ${ }^{8}$ by depicting a leader exercising minimal effort to get necessary work done and showing negligible concern for subordinates. ${ }^{9}$

\section{Absentee Leader}

According to Harvard Business Review, Absentee leader are the people who are occupying the leadership roles, but rarely act as a leader. They are physically present in the organisations but are absent psychologically from their role. These types of leaders are termed to be rent seeking, where benefit is taken out of the organization but no return to those benefits are provided back to the organisation. This means they enjoy perks and privileges, but they avoid being meaningfully involved with their employees and teams. The effects of absentee leader over organisations takes long to be visible and are long lasting in nature.
One of the major concerns here is that inspite of such negative and long-lasting influences of absentee leader, we generally don't listen much about them and no actions are taken against them. The reason behind such treatment of absentee leader lies in the fact that they rarely get any negative attention. Since they are passive in nature, most of the times those leaders or even members of the organisation who are more overt in their negative behaviour get all the attention and management somehow ignores or overlooks the problems caused by them. It is always difficult to find problems with absentee leaders as they rarely hurt the sentiments of anyone around them directly and hence no one thinks of raising a voice against them. But the fact remains that these leaders because of their passivity fail to provide any constructive feedback to the team. They also fail to recognize the achievements of their employees. Absentee leaders hardly ever engage in inexcusable bouts of bad conduct and are rarely the matter of ethics probes stemming from employee hotline calls. As a result, their adverse effect on organizations accumulates over time, mostly unchecked.

There is a very thin line of difference between Laissez Faire leadership and absentee leadership. The latter is more destructive in nature. It results in increased role ambiguity of employees, higher mistakes, and less performance due to lack of proper feedback provided by the absentee leader. Without a clear vision of the organisation's direction because of lack of communication between leader and employees, the organisations fail to realise its objectives. Because of lack of communication, direction and feedback the talent drain of the organisation also reaches at peaks. Left unrestricted, absentee leaders block an organization's succession arteries, preventing possibly more useful people from moving into critical roles while improving little productivity.

\section{Source of Funding}

None.

\section{Conflict of Interest}

The authors declare that there is no conflict of interest regarding the publication of this article.

\section{References}

1. Tannenbaum A, Schmidt W. How to choose a leadership pattern. Harvard Business Rev, 1958;36:95-101.

2. Bass BM, Avolio BJ. (1995). MLQ Multifactor Leadership Questionnaire for research: permission set Mindgarden, Redwood City, CA.

3. Antonakis J, Avolio BJ, Sivasubramaniam N. (2003). Context and leadership: an examination of the nine-factor full-range leadership theory using the Multifactor Leadership Questionnaire. Leadersh Q. 2003;14(3):261-95.

4. Keegan AE, Den Hartog DN. (2004). Transformational leadership in a project-based environment: a comparative study of the leadership styles of project managers and line managers. Int J Project Manag. 2004;22(8):609-17.

5. Bass B, Avolio J. (1990). The Multifactor Leadership Questionnaire, Palo Alto, CA: Consulting Psychologists Press

6. Pearce JL. (1981). Bringing some clarity to role ambiguity research. Acad Manag Rev. 1981;6(4):665-74. 
7. Northouse, P. G. (2010). Leadership: Theory and Practice.

8. Blake R, Mouton J. (1985). The Managerial Grid III: The Key to Leadership Excellence. Gulf Publishing Co, Houston.

9. Einarsen S, Aasland MS, Skogstad A. Destructive leadership behaviour: A definition and conceptual model. Leadersh $Q$. 2007:18(3):207-16
How to cite this article: Achhnani B. Thin line of difference between laissez faire leadership and absentee leader. J Manag Res Anal. 2020;7(4):183-5. 